\title{
Reflexões sobre ações educativas para migrantes internacionais: diálogos com a pedagogia social
}

\author{
Ana Cristina Kerbauy Vigar ${ }^{1}$ \\ Janaina Silva Gondin ${ }^{2}$
}

\begin{abstract}
Resumo: Nos últimos anos do século XX e no início do século XXI, as transformações econômicas, políticas e culturais no cenário mundial influenciaram fortemente o fluxo migratório, tornando-o, novamente, uma temática de destaque no Brasil. Sabe-se que uma parte considerável dos migrantes chega ao país sem possuir domínio da língua portuguesa e perspectiva de trabalho. Logo, buscam associações e instituições que atuam como suporte de acolhida, instrução e orientação, auxiliando-os na inserção social. Nesse contexto, o objetivo deste artigo é discutir como a Pedagogia Social e suas práticas de Educação popular, comunitária e social podem contribuir para o processo educacional dos migrantes em situação de vulnerabilidade no Brasil. Parte-se do pressuposto de que é urgente refletir sobre as práticas para superação de obstáculos enfrentados por grupos migratórios na chegada no novo país. Ao final, discorre-se sobre a importância das práticas da Pedagogia Social na promoção de equidade de direitos entre cidadãos brasileiros e migrantes internacionais.
\end{abstract}

Palavras-chave: Migrantes internacionais. Pedagogia social. Educação popular.

\section{Reflections on educational actions for international migrants: dialogues with social pedagogy}

\begin{abstract}
In the last years of the twentieth century and the beginning of the twenty-first century, there have been major economic, political and cultural transformations, which strongly influenced the flow of migrants, drawing public attention in Brazil. A considerable number of migrants, who arrive in the country without speaking the Portuguese language and without any job perspective, seek associations and institutions that provide instruction and guidance to facilitate their settlement in the Brazilian society. In this context, the objective of this article is to discuss how Social Pedagogy and popular communitarian and social Education practices can contribute to the educational process of migrants in state of vulnerability in Brazil. It is urgent to reflect on elements that contribute to practices committed to overcoming obstacles faced by migratory groups upon arrival in the new country. Finally, we discuss the importance of practices of Social Pedagogy in the promotion of equity rights between Brazilian citizens and international migrants.
\end{abstract}

Keywords: International migrants. Social Pedagogy. Popular education.

\section{INTRODUÇÃO}

Há milhares de anos, o ser humano desloca-se de um local para outro em busca de alimento, proteção e melhores condições de adaptação e conforto. Esses movimentos sempre

\footnotetext{
${ }^{1}$ Doutoranda do Programa de Doutorado em Língua Portuguesa (Linguística Aplicada) da Universidade de São Paulo (USP). Possui Bacharelado em Letras, habilitação Português e Francês - USP (2004); Licenciatura, habilitação Português e Francês - USP (2005) e Mestrado em Literatura Portuguesa pela mesma Universidade (2008). E-mail: akerbauy@usp.br.

${ }^{2}$ Professora de Educação Infantil na Prefeitura Municipal de São Paulo. Mestra em Ciências Humanas e Sociais pela Universidade Federal do ABC e Doutoranda em Educação pela Universidade de São Paulo. E-mail: janaina2202@gmail.com.
} 


\title{
MTIFARIUS REFLECTLNIS
}

Revista Eletrônica de Graduação e Pós-Graduação em Educaçāo

ocorreram na história da humanidade, contudo houve algumas mudanças nas últimas décadas.

Castles e Miller (2009) apontam que os movimentos migratórios atuais adquiriram uma importância antes não vista.

\begin{abstract}
Os movimentos populacionais sempre acompanharam o crescimento demográfico, a mudança tecnológica, o conflito político e a guerra. Nos últimos cinco séculos, a migração em massa desempenhou um papel importante no colonialismo, na industrialização, na formação dos estados nacionais e no desenvolvimento do mercado mundial capitalista. No entanto, a migração internacional nunca foi tão difundida, nem tão significativa em termos socioeconômicos e políticos quanto é hoje. Nunca antes os líderes políticos atribuíram tal prioridade às preocupações com a migração. Nunca antes a migração internacional parecia tão pertinente à segurança nacional e tão conectada a conflitos e à desordem em escala global ${ }^{3}$. (CASTLES; MILLER, 2009, p. 299, tradução nossa).
\end{abstract}

A partir do século $\mathrm{XX}$, as inovações tecnológicas e no setor de transportes possibilitaram deslocamentos cada vez maiores e mais frequentes. Mudanças na produção mundial e expansão do processo de globalização dos mercados de trabalho podem ser apontados como fatores responsáveis pela intensificação desses movimentos. "A partir da eletrônica, compreendendo a telecomunicação, o computador, o fax e outros meios, o mundo dos negócios agilizou-se em uma escala jamais conhecida, desterritorializando coisas, gentes e ideias". (IANNI, 1996, p. 3).

No contexto mundial, com um trânsito populacional crescente, as comunidades sociais, de forma geral, precisam planejar seu futuro considerando os efeitos da mobilidade humana. Ianni (1996) aponta que a globalização expressa um novo ciclo de expansão do capitalismo, de alcance mundial, criando uma nova divisão internacional do trabalho: "A nova divisão internacional do trabalho envolve a redistribuição das empresas, corporações e conglomerados por todo o mundo". (IANNI, 1996, p. 2).

É cada vez mais comum que os Estados se tornem, simultaneamente, países de origem, trânsito e destino. O processo migratório é bastante complexo e apresenta diversos desafios, por isso torna-se necessária a cooperação entre os Estados para superar os desafios.

\footnotetext{
${ }^{1}$ No texto original: "Population movements have always accompanied demographic growth, technological change, political conflict and warfare. Over the last five centuries, mass migration have played a major role in colonialism, industrialization, nation-station formation and the development of the capitalist world market. However, international migration has never been as pervasive, or as socioeconomically and politically significant, as it is today. Never before have political leaders accorded such priority to migration concerns. Never before has international migration seemed so pertinent to national security and so connected to conflict and disorder on a global scale". (CASTLES; MILLER, 2009, p. 299).
} 


\title{
IrWeparins REFLECTIONIS
}

Revista Eletrônica de Graduação e Pós-Graduação em Educaçāo

Visto a relevância do tema, em vários países, a migração tem sido inserida nas estratégias de desenvolvimento.

Nesse cenário global, o Brasil, apesar de apresentar ainda um número pequeno de migrantes internacionais, tem sido a escolha de muitos grupos migratórios nos últimos anos. $\mathrm{O}$ país que foi constituído a partir da entrada de diferentes povos, passou décadas fora do cenário dos grandes deslocamentos populacionais, ganhando destaque novamente na contemporaneidade.

\begin{abstract}
Nos anos 2000, sobretudo na segunda metade dessa década, passou-se a observar um incremento nos fluxos imigratórios no País, deslocamentos que trouxeram uma parcela importante de brasileiros retornados e estrangeiros. Esse aumento no volume das entradas, como já referido, pode ser explicado, entre outros fatores, principalmente pelo desenvolvimento sustentável das atividades econômicas no Brasil e pelo agravamento da crise do capitalismo no mundo desenvolvido, que atingiu profundamente países com os quais o Brasil mantinha historicamente relações de trocas populacionais (Estados Unidos, Portugal, Espanha, Japão e Itália). (OLIVEIRA, 2013, p. 207).
\end{abstract}

Com o intuito de compreender as razões para o aumento do fluxo migratório no Brasil, Oliveira (2013) aponta dois fatores principais: I) a estabilidade econômica, sustentando o desenvolvimento das atividades produtivas desde a segunda metade dos anos 1990, e II) a crise financeira que afetou consideravelmente os países desenvolvidos desde 2008. Esses fatores não só atraíram migrantes internacionais, como também contribuíram para o retorno de muitos brasileiros que moravam no exterior e sofreram com a crise econômica desencadeada no Estados Unidos, Europa e Ásia entre 2007 e 2008.

Tradicionalmente, o Brasil já estava acostumado com os deslocamentos envolvendo as populações de países fronteiriços, pois, segundo Baeninger (2012), esses deslocamentos populacionais entre os países latino-americanos são históricos, complexos e compreendem diversas formas de mobilidade, derivando, principalmente de fatores econômicos e políticos.

O final do Século 20 e o início do Século 21 revelaram enormes transformações econômicas, sociais, políticas, demográficas e culturais em âmbito internacional com fortes rebatimentos nos contextos da imigração latino-americana e do Brasil. As mudanças advindas do processo de reestruturação da produção implicam a mobilidade do capital e da população em diferentes partes do mundo. Nesse cenário, o Brasil também passou a se inserir, com reflexos na configuração de um novo contexto das migrações internacionais para o país (BAENINGER, 2012, p. 9). 


\section{ITHerapuns REFLECTIONIS}

Revista Eletrônica de Graduação e Pós-Graduação em Educaçāo

Apesar desse ingresso ocorrer comumente através das fronteiras terrestres, muitos migrantes não se fixam nessas regiões fronteiriças, deslocando-se para outros locais da federação. Bógus e Fabiano (2016) apontam que, de acordo com Censo de 2010, o estado com maior fluxo de migrantes internacionais é São Paulo, que corresponde a cerca de $30,7 \%$ do número total, ficando à frente do Paraná $(14,6 \%)$, de Minas Gerais $(9,8 \%)$ e do Rio de Janeiro $(7,6 \%)$.

Mesmo tratando-se ainda de um número pequeno quando comparado ao exército de pessoas que adentram diariamente os países ditos desenvolvidos, muitos migrantes que chegam ao Brasil não encontram uma estrutura adequada para recebê-los. Assim, acabam buscando instituições que lhes ofereçam abrigo, proteção e auxílio para conseguir um emprego. Essas organizações geralmente surgem a partir da sociedade civil e atuam como ponte essencial para a inclusão dessa população na nova terra.

Uma grande barreira que essa população enfrenta ao chegar é a língua, que se torna um dificultador na busca por orientações sobre documentação e especialmente na busca por uma vaga de emprego. Nesse contexto, as instituições que atuam com a instrução, orientação e formação desse público, exercem um papel fundamental na reconstrução de suas vidas.

Neste artigo, discutiremos sobre a atuação das organizações da sociedade civil que atuam no âmbito educacional, relacionado às práticas de Pedagogia Social, tratando especificamente dos migrantes que necessitam do acolhimento e apoio dessas instituições para garantir acesso a bens e serviços durante seu tempo de permanência no país.

Dessa forma, este trabalho tem o objetivo de refletir sobre as contribuições das práticas de Pedagogia Social para superação dos empasses enfrentados por esses migrantes na sua chegada ao Brasil.

Para isso, o texto está organizado em três partes: na primeira, discorre-se sobre a legislação relacionada à migração no país; na segunda, discute-se sobre conceitos da Pedagogia Social, e na última, busca-se refletir, à luz da Pedagogia Social, sobre o direito e o acesso à educação pelos migrantes no Brasil, para superação de desafios envolvidos na acolhida e inserção social.

\section{MARCOS LEGISLATIVOS PARA MIGRANTES}




\section{ITHerapuns REFLETIONIS}

Revista Eletrônica de Graduação e Pós-Graduação em Educaçāo

Algumas estratégias têm sido criadas, com a pressão da sociedade civil, para lidar com as demandas do fluxo migratório no Brasil. Resultado de um processo de oito anos, a nova Lei de Migração $n^{\circ} 13.445$ foi sancionada recentemente em 2017, em substituição ao Estatuto do Estrangeiro, Lei n ${ }^{\circ} 6.815 / 80$.

A Lei de Migração representa um avanço para a integração social e a proteção de direitos de migrantes. Há um caminho político-social que vem sendo trilhado através da ruptura com o antigo Estatuto, que não mais respondia às mudanças atuais da realidade no país. Apesar das limitações da nova lei diante dos vetos governamentais, observa-se a abertura para uma nova perspectiva de direitos humanos.

As mudanças legislativas foram frutos da colaboração da sociedade civil organizada, dos grupos de trabalho e dos movimentos sociais. Através de elaboração de notas técnicas, emendas e sugestões, além de inúmeras reuniões e pressões ao governo, merece destaque a participação de instituições como: Missão Paz, Caritas Arquidiocesana de São Paulo, Conectas Direitos Humanos, Instituto Terra Trabalho e Cidadania (ITTC), Serviço Franciscano de Solidariedade (Sefras), de São Paulo, e Centro de Estudios Legales y Sociales (CELS), de Buenos Aires.

O Estatuto do Estrangeiro foi revogado por ser desatualizado e inconstitucional, por criminalizar o migrante, vendo-o como uma ameaça para a segurança social (Lei $n^{\circ}$ 6.815/80, art. 2). Em contrapartida, na Lei de Migração, baseada nos princípios da Constituição de 1988 e nos tratados internacionais ratificados pelo Brasil, o migrante é considerado "sujeito de direitos" (Lei 13.445/17, art. 3 e 4), passando a ser assegurado por alguns dos mesmos direitos garantidos pelos brasileiros, como participar de protestos e se filiar a sindicatos, até então proibidos (Lei n 6.815/80, art. 106 e 107).

Além disso, enquanto o Estatuto do Estrangeiro dificultava a regularização (art. 38), a Lei de Migração busca desburocratizar os procedimentos de regularização (art. 3), prevendo a concessão de visto humanitário para acolhida especial, categoria usada inicialmente para haitianos e depois estendida a sírios e venezuelanos.

Regida pelo princípio de não-criminalização da migração, em refutação à criminalização, deportação e expulsão previstas (Lei n 6.815/80, art. 57, 61, 62 e 66), a Lei de Migração oferece o devido processo legal, acesso à justiça, prevendo também a formulação e o acesso às políticas públicas (Lei 13.445/17, art. 4). 


\section{ITHerapuns REFLECTIONIS}

Revista Eletrônica de Graduação e Pós-Graduação em Educaçāo

No âmbito municipal, também merecem destaque as iniciativas públicas e da sociedade civil que visam a garantia dos direitos, sobretudo educativos, de migrantes em São Paulo. Em 2013, foi criada a Coordenação de Políticas para Migrantes (CPMig), ligada diretamente à Secretaria Municipal de Direitos Humanos e Cidadania (SMDHC), cujo objetivo é articular as políticas públicas migratórias no município.

Em 2014, foi inaugurado o primeiro Centro de Referência e Atendimento para Imigrantes (CRAI-SP), em que são oferecidos serviços especializados para a população migrante organizados em setores: atendimento jurídico, psicológico, socioassistencial, cursos e oficinas, além da capacitação de servidores públicos e construção de abrigos.

Em 2016, as mudanças culminaram em um marco pioneiro em São Paulo com a aprovação da Lei Municipal $n^{\circ} 16.478$, que institui a Política Municipal para a População Imigrante (PMPI). Trata-se de uma norma jurídica que dispõe sobre diretrizes e prioridades, estabelecendo o funcionamento de um Conselho Municipal de Migrantes. É a primeira lei do país a instituir direcionamento para a construção de uma política pública migratória no âmbito municipal.

Sabe-se que as bases políticas e legislativas influenciam o desenvolvimento da educação. Pretende-se, aqui, destacar no surgimento dessas novas legislações e normatizações a importância dada à garantia da educação como um direito social do migrante.

Na Lei de Migração (n 13.445/17), há duas citações da palavra "educação". No artigo $3^{\circ}$, inciso XI, reconhece-se a educação como uma garantia do migrante, assim como o "acesso igualitário" a serviços e à assistência pública. No artigo $4^{\circ}$, inciso X, afirma-se que, também em igualdade com os brasileiros, o direito à educação deve ser assegurado, sendo "vedada a discriminação em razão da nacionalidade e da condição migratória".

Na Lei municipal, em que a política para a população migrante é instituída, garantese com prioridade o direito à educação pública na rede municipal para migrantes de todas as idades: "crianças, adolescentes, jovens e pessoas adultas", durante todo o processo educativo “do seu acesso, permanência e terminalidade" (Lei n 16.478/16, art. $7^{\circ}$, IV).

Com efeito, a lei é uma ferramenta de institucionalização de políticas públicas. $\mathrm{O}$ avanço atual se dá no reconhecimento da obrigação do Estado e do município na assistência aos migrantes. Porém, a legitimação dos direitos previstos apenas irá se concretizar de fato na sua regulamentação, através da consolidação das políticas e da participação da sociedade. 


\section{ITWeparius REFLECTIONIS}

Revista Eletrônica de Graduação e Pós-Graduação em Educaçāo

Essas mudanças legislativas, tanto no âmbito nacional quanto municipal, são respostas à nova estrutura e demanda mundial. Assim, representam um marco nos movimentos migratórios por dialogarem, em uma instância maior, com as garantias reconhecidas na Declaração Universal dos Direitos Humanos.

\section{CONTRIBUIÇÕES DA PEDAGOGIA SOCIAL PARA MIGRANTES EM SITUAÇÃO DE VULNERABILIDADE}

Ao chegar ao Brasil, a maioria dos migrantes não tem onde ficar e muito menos um trabalho para sobrevivência. Frequentemente, isso ocorre porque a mudança de país não estava prevista inicialmente, ocorrendo após episódios marcantes, tais como crises políticas, econômicas ou catástrofes ambientais em seus países de origem. Consequentemente, esses grupos migratórios chegam completamente desamparados e desconhecendo o que encontrarão pela frente. Assim, buscam apoio em instituições e associações que, por oferecem moradia, cursos de língua portuguesa e orientação para inserção no mercado de trabalho nacional a grupos migratórios em situação de vulnerabilidade, cumprem, de acordo com a Pedagogia Social, um papel de promotores de práticas de Educação social, popular e comunitária.

A Pedagogia Social é uma ciência pedagógica, de caráter teórico e prático, em referência à socialização do sujeito e de grupos, cujo objetivo principal é responder às necessidades de sua realidade. Dessa forma, o objetivo da Pedagogia Social é auxiliar o convívio em comunidade, contribuindo para a integração do indivíduo ao seu meio social e capacitando-o, ao mesmo tempo, para as possibilidades de transformação do seu próprio locus. (DIAZ, 2006).

A prática dessa abordagem, chamada de Educação Social, dá-se em diversos contextos, não só dentro, mas também fora das instituições escolares, já que o processo de socialização engloba a vida dos sujeitos como um todo: as relações com a família, na escola e em sua comunidade, em um tempo contínuo de realidades (DIAZ, 2006).

A Teoria Geral da Educação Social que fundamenta as práticas de Educação Social, Educação Popular e Educação Comunitária é, por definição, inter e multidisciplinar, mas pressupõe uma visão de homem, de sociedade e de mundo na qual a natureza das relações e a qualidade destas devam ser essencial e predominantemente pedagógicas e se sobrepõem a qualquer dogmatismo ou doutrinação (DA SILVA, 2016, p. 192). 
Conforme aponta Da Silva (2016), a Pedagogia Social possui diferentes perspectivas e tradições, que surgiram em diversos países. A vertente latino-americana, estruturada a partir do Brasil, apresenta como matriz a educação popular e possui como principais referências teóricas os trabalhos de Paulo Freire e educadores locais.

Mesmo que Freire nunca tenha utilizado o termo Pedagogia Social em suas obras, Da Silva (2016) afirma que a epistemologia freiriana e sua convicção de que a educação precisa garantir liberdade, emancipação e autonomia dá suporte para compreensão que a Pedagogia Social não é destinada apenas aos excluídos socialmente, mas sim a todos e todas, pois, como o próprio Freire afirmava, a educação deve libertar tanto oprimidos quanto opressores.

\begin{abstract}
A concepção de uma Pedagogia Social fundamentada no pensamento pedagógico de Paulo Freire representa uma importante contribuição para a pesquisa, análise e reflexão das ricas e diversificadas práticas de educação popular, comunitária e social oriundas dos movimentos sociais e populares, por vezes fragilizadas por falta de fundamentação teórica, marginalizada pela academia, desprovida de instâncias de formação e com produção completamente fragmentada, sem nenhuma organicidade teórica ou conceitual (DA SILVA, 2016, p. 188-189).
\end{abstract}

Didaticamente, a Pedagogia Social organiza-se em três grandes práticas: Educação

Social, educação popular e educação comunitária.

\begin{abstract}
A Pedagogia Social e suas práticas - sejam elas Educação Social, popular ou comunitária - pressupõe o entendimento de que Educação se faz ao longo de toda a vida, em todos os espaços e que todos nós somos potenciais educadores. Nenhum espaço seja público ou privado, e nenhum grupo social, qualquer que seja sua capacidade econômica ou nível de escolaridade pode prescindir da Pedagogia Social, especialmente nestes tempos de intensas transformações nas relações em todas as instâncias e estruturas sociais (DA SILVA, 2016, p. 189).
\end{abstract}

Assim, a Pedagogia Social não se prende a espaços ou formações, considerando que qualquer pessoa possa se tornar uma educadora, ao considerar que a educação vai além das paredes de uma instituição.

Segundo Graciani (2006), a Pedagogia Social é um processo de transformação política e social que:

[...] a) propõe inicialmente criar uma teoria renovada de relação homem, sociedade e cultura, com uma ação pedagógica que pretende fundar, a partir do exercício em todos os níveis e modalidades da prática social, uma educação libertadora; b) realiza-se no domínio específico da prática social com classes sociais populares, a partir de um trabalho político educacional de libertação popular, com o intuito de ser conscientizador com sujeitos, grupos e movimentos das camadas excluídas; c) 
concretiza-se como ação educativa com agentes e sujeitos comprometidos, onde se estabelece através da relação dialógica, um sistemático processo de intercâmbio de conhecimento e saberes, onde a troca de experiências é primordial; d) orienta-se pela pedagogia libertadora protagônica baseada fundamentalmente na memória histórica na identidade coletiva, na dinâmica cultural, na possibilidade entre a capacidade lógica de compreender os liames capitalistas e a valorização da participação comunitária e, auto-estima, auto-valorização, autoconfiança e autodeterminação de sujeitos que tentam construir uma nova ordem social, econômica e cultural (GRACIANI, 2006).

A abrangência da Pedagogia Social, cujas considerações podem ser significativas no âmbito coletivo, proporcionam contribuições para o desenvolvimento da educação voltada a migrantes, especialmente àqueles que estão em situação de vulnerabilidade e necessitam de suporte para garantia da sua permanência e inserção no país.

Com efeito, avanços nas leis e nas ações de políticas públicas para migrantes têm sido notados. Contudo, não há garantia da eficácia, na prática, de direitos econômicos e sociais, dentre eles o acesso à educação, para esses sujeitos que mudam de status, frequentemente, de recém-chegados para marginalizados.

Nesse cenário, é importante refletir, através da Pedagogia Social em que a valorização da cultura, da capacidade de aprendizado e da participação comunitária são consideradas, sobre ações educativas que englobem as instâncias públicas, os educadores e a sociedade como um todo, a fim de construir um caminho para a cidadania do migrante no Brasil.

\section{PRÁTICAS dA PEDAgOGIA SOCIAL COMO APORTES PARA A EDUCAÇÃO DE MIGRANTES}

De acordo com o Alto Comissariado das Nações Unidas para os Refugiados (ACNUR), o Brasil é signatário dos principais tratados migratórios. Ao receber um número crescente de migrantes, o Estado tem o desafio e a responsabilidade de atender às mudanças sociais, criando políticas que visem a garantia dos direitos e a integração social da população.

Nesse contexto, a teoria da Pedagogia Social e sua práxis são pertinentes para se pensar em políticas públicas que respondam às necessidades desse público. Quando se visa a integração e a cidadania de uma população migratória, é importante promover ações educacionais através das quais o migrante possa "agir" em diversos contextos na nova sociedade e, sobretudo, no mercado de trabalho. 


\section{ITINPARIus REFLECTIONIS}

Revista Eletrônica de Graduação e Pós-Graduação em Educaçāo

Essa abordagem pode contribuir para o desafio de inserção social do migrante, através da valorização e do desenvolvimento de suas habilidades e competências:

[...] a educação seria o processo de transformação do indivíduo biológico em indivíduo social, seria a aquisição das capacidades para participar e integrar-se no grupo no qual the corresponde viver. Contudo, a Educação Social, para além de solucionar determinados problemas de convivência, tem uma função não menos importante, que é a de ser um instrumento igualitário e de melhoria da vida social e pessoal (DIAZ, 2006, p. 103).

Nesse sentido, o Marco de Referência da Educação Popular para as Políticas Públicas (2014), que é um documento sobre a importância da educação popular e as diretrizes para criação de políticas públicas, serve de base para elaboração de ações para migrantes. Em respostas às demandas de grupos excluídos de direitos, tem como objetivo valorizar as práticas sociais e educacionais a partir da concepção educacional freireana.

O propósito desse documento é "criar um conjunto de elementos que permita a identificação de práticas de Educação Popular nos processos das políticas públicas, estimulando a construção de políticas emancipatórias" (BRASIL, 2014, p. 5). Para isso, faz-se necessário o trabalho conjunto entre setores governamentais e da sociedade civil, a fim de englobar todos os agentes do processo educacional.

É interessante notar que o desenvolvimento de políticas públicas tem se dado “dentro e fora” de instâncias governamentais, através de diálogos entre universidades públicas, centros de Educação popular, Organizações Não Governamentais (ONGs) e movimentos sociais, com a finalidade de responder às demandas dos sujeitos sociais. Nesse contexto, a parceria entre sociedade civil e Estado ganha ainda mais importância na construção de projetos que viabilizem a inserção dos migrantes.

Tanto o direito social à educação quanto o direito político de inserção e cidadania, que fundamentam as bases históricas da educação, são aqui referenciados: a educação popular “é vista como formadora da consciência nacional, de um projeto de nação soberano e igualitário, potencializadora de transformações político-sociais profundas, formadora da cidadania e da relação com o mundo do trabalho" (BRASIL, 2014, p. 17).

Assim, as políticas públicas para migrantes, quando pautadas na educação popular, podem transformá-los em sujeitos de direitos, fortalecendo sua autonomia, em um processo educativo que responda às suas necessidades, valorize seus saberes, insira-os no mercado de 


\section{ITHerapuns REFLECTLNIS}

Revista Eletrônica de Graduação e Pós-Graduação em Educaçāo

trabalho, criando um vínculo entre a realidade do educando, as práticas sociais e a própria experiência educativa.

A representação das diferenças culturais, de valores e as regras intrínsecas podem ser valorizadas, a fim de possibilitar uma educação que englobe a realidade do sujeito. Com efeito, a afetividade, a cultura, os valores e as crenças são relevantes, pois afetam os agentes envolvidos: o educador e o educando.

O conceito de "dialogismo" freiriano é apontado como um dos pilares das ações de políticas públicas. Partindo do pressuposto que o trabalho pedagógico é conflituoso por considerar saberes de sujeitos sociais diferentes, o diálogo entre esses agentes na educação popular é o processo que possibilita:

[...] a troca de significados e o aprofundamento na compreensão dos elementos constitutivos da realidade, oportunizando a reconstituição simbólica do real, permitindo a construção de significados comuns, o aprofundamento da solidariedade e a elaboração de alternativas para a superação das compreensões fatalísticas a respeito do que se passa na vida cotidiana (BRASIL, 2014, p. 23).

Logo, cabe ao educador reconhecer as especificidades e os desafios da realidade do educando, assumindo o papel de intermediário da aprendizagem e também de amenizador do conflito inicial.

À luz da Pedagogia Social, o educando é visto como sujeito de direitos e autônomo, cuja participação se dá no âmbito sociocultural e econômico. Desse modo, é urgente a promoção de ações educativas direcionadas para que o migrante consiga adentrar o espaço laboral, que é o lugar primordial para sua inserção, a partir do qual poderá reconstruir sua vida e da sua família.

\section{CONSIDERAÇÕES FINAIS}

O processo migratório continua a aumentar em escopo, complexidade e impacto no século XXI. Nunca antes se registrou um número tão grande de pessoas se deslocando pelo mundo, entrando e saindo de diferentes países e regiões.

Esse grande fluxo impõe mudanças nas políticas do Estado e, especialmente, na forma de lidar com esse desafio. 


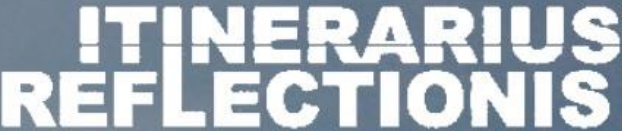

Revista Eletrônica de Graduação e Pós-Graduação em Educaçāo

As novas modalidades migratórias demandam, no cenário da globalização, a necessidade de reavaliação dos paradigmas para o conhecimento e o entendimento das migrações internacionais no mundo, e a incorporação de novas dimensões explicativas torna-se imprescindível, assim como a própria definição do fenômeno migratório deve ser revista. (PATARRA, 2006, p.7).

Nota-se de forma crescente o reconhecimento do indivíduo como portador de direitos, independentemente de nacionalidade. Contudo, há ainda grande dificuldade na implementação desses direitos, que continuam ainda dependentes dos Estados, especialmente os que recebem os migrantes.

Essas mudanças implicam a criação de um sistema verdadeiramente dinâmico de mobilidade humana, que requer formuladores de políticas em todos os níveis de governo para trabalhar de forma colaborativa.

Os migrantes, por terem passado por experiências muitas vezes traumáticas e sofrido violações de direitos, falarem outras línguas que não o português e possuírem culturas e crenças distintas, demandam um olhar específico dos governos e da sociedade.

Nesse sentido, a Pedagogia Social contribui para a compreensão das especificidades desse público e para solução de suas demandas, enquanto as práticas de Educação popular, comunitária e social, exercidas pelas instituições de acolhida desses grupos migratórios, auxiliam na superação dos impasses que surgem durante seu deslocamento e na acolhida no Brasil.

Mesmo que políticas públicas, acompanhadas por mudanças na legislação, tenham surgido como respostas às demandas desse grupo, há um longo caminho a ser percorrido para uma efetiva inserção social e espera-se que as contribuições da Pedagogia Social possam assessorar no desenvolvimento de ações que garantam aos migrantes os mesmos direitos que aos cidadãos brasileiros.

\section{REFERÊNCIAS}

BAENINGER, Rosana. O Brasil na rota das migrações latino-americanas. In: BAENINGER, Rosana (org.). Imigração Boliviana no Brasil. Campinas: Núcleo de Estudos de PopulaçãoNepo/Unicamp; Fapesp; CNPq; Unfpa, 2012.

BÓGUS, Lucia Maria Machado; FABIANO, Maria Lucia Alves. O Brasil no contexto das migrações internacionais recentes. In: RODRIGUES, Leda Maria de Oliveira (org.). Imigração atual: dilemas, inserção social e escolarização: Brasil, Argentina e EUA. São Paulo: Escuta, 2017. 
BRASIL. ACNUR. Refúgio no Brasil. Brasília, 2004. Disponível em: https://www.acnur.org/fileadmin/Documentos/portugues/Estatisticas/Refugio_no_Brasil_201 0_2014.pdf. Acesso em: 22 jun. 2019

BRASIL. Congresso Nacional. Lei n. 13.445, de 24 de maio de 2017. Institui a Lei de Migração. Disponível em: http://www.planalto.gov.br/ccivil_03/_ato20152018/2017/lei/L13445.htm. Acesso em: 11 nov. 2018.

BRASIL. Lei ${ }^{0}$ 6.815, de 19 de agosto de 1980. Define a situação jurídica do estrangeiro no Brasil, cria o Conselho nacional de Imigração (Lei revogada). Disponível em: http://www.planalto.gov.br/ccivil_03/LEIS/L6815.htm. Acesso em: 12 nov. 2018.

BRASIL. Secretaria Nacional de Articulação Social. Marco de Referência da Educação Popular para as Políticas Públicas. Departamento de Educação Popular e Mobilização Cidadã. Brasília, 2014.

CASTLES, Stephen; MILLER, Mark J. The age of migration: International population movements in the modern world. New York: Palgrave Macmillan, 2009, p. 50-78; 299-312.

DA SILVA, Roberto. Os fundamentos freireanos: da Pedagogia Social em construção no Brasil. Pedagogia Social Revista Interuniversitaria, v.1, n.27, p. 179-198, 2016.

DIAZ, Andrés Soriano. Uma aproximação à Pedagogia: Educação Social. Revista Lusófona de Educação, n. 7, p. 91-104, 2006.

ESTEBAN, José Ortega. Pedagogía Social y Pedagogía Escolar: la educación social en la escuela. Revista de Educación, n. 336, p. 111-127, 2005.

GRACIANI, Maria Stela Santos. Pedagogia Social: impasses, desafios e perspectivas em construção. In: I CONGRESSO INTERNACIONAL DE PEDAGOGIA SOCIAL, Ano 1, 2006. Proceedings online... Faculdade de Educação, Universidade de São Paulo, Disponível em: http://www.proceedings.scielo.br/scielo.php?script=sci_arttext\&pid=MSC00000000 92006000100038\&lng=en\&nrm=abn. Acesso em: 07 nov. 2018.

IANNI, Octavio. Globalização e Diversidade. In: PATTARRA, Neide Lopes (Org.). Migrações Internacionais: herança XX, agenda XXI. Campinas: FNUAP; São Paulo: Oficina Editorial, 1996.

MINISTÉRIO DA JUSTIÇA E CIDADANIA (MJC). Nota à imprensa: Esclarecimento sobre concessão de vistos humanitários aos haitianos. Brasília: 2016. Disponível em: http://justica.gov.br/noticias/nota-a-imprensa-29. Acesso em: 10 nov. 2018.

OLIVEIRA, Antônio Tadeu Ribeiro de. Um panorama da migração internacional a partir do censo demográfico de 2010. Rev. Inter. Mob. Hum. Brasília, Ano XXI, n. 40, p. 195-210, jan./jun. 2013. Disponível em: http://www.scielo.br/pdf/remhu/v21n40/12.pdf. Acesso em: 20 out. 2018. 


\section{ITHerapuns REFLETIONIS}

Revista Eletrônica de Graduação e Pós-Graduação em Educaçāo

PATARRA, Neide Lopes. Migrações internacionais: teorias, políticas e movimentos sociais. Estudos Avançados, São Paulo, v. 20, n. 57, ago. 2006. Disponível em: http://www.scielo.br/pdf/ea/v20n57/a02v2057.pdf. Acesso em: 06 set. 2018.

PORTAL DA PREFEITURA DE SÃO PAULO. Política Municipal para População Imigrante. Disponível em: http://www.prefeitura.sp.gov.br/cidade/secretarias/direitos _humanos/migrantes/programas_e_projetos/index.php?p=205909. Acesso em: 13 nov 2018.

SÃO PAULO. Câmara Municipal de São Paulo. Lei Municipal n.16.478, de 8 de julho de 2016. Institui a Política Municipal para a População Imigrante, dispõe sobre seus objetivos, princípios, diretrizes e ações prioritárias, bem como sobre o Conselho Municipal de Imigrantes. Disponível em: http://www.prefeitura.sp.gov.br/cidade/secretarias/upload/direitos_humanos /LEI\%2016478.pdf. Acesso em: 15 nov. 2018.

SÃO PAULO. Secretaria Municipal de Educação. Portaria 6837/14 de 23 de dezembro de 2014. Dispõe sobre normas gerais do Regime Escolar dos educandos da Educação Infantil, do Ensino Fundamental e Médio, da Educação de Jovens e Adultos e da Educação Profissional da Rede Municipal de Ensino, e dá outras providências. Disponível em: http://www3.prefeitura.sp.gov.br/cadlem/secretarias/negocios_juridicos/cadlem/ integra.asp?alt=24122014P\%20068372014SME\%20\%20\%20\%20\%20\%20\%20\%20\%20\&se cr $=150 \& d e p t o=0 \& d e s c r \_t i p o=P O R T A R I A$. Acesso em: 10 nov. 2018. 